\title{
BMJ Open Patient Continuity of Care Questionnaire in a cardiac sample: A Confirmatory Factor Analysis
}

\author{
Emma Säfström (D) , ${ }^{1,2}$ Lena Nasstrom, ${ }^{3}$ Maria Liljeroos, ${ }^{1,2}$ Lena Nordgren,,${ }^{2,4}$ \\ Kristofer Årestedt, ${ }^{5}$ Tiny Jaarsma, ${ }^{1}$ Anna Stromberg ${ }^{1,6}$
}

To cite: Säfström E, Nasstrom L, Liljeroos M, et al. Patient Continuity of Care Questionnaire in a cardiac sample: A Confirmatory Factor Analysis. BMJ Open 2020;10:e037129. doi:10.1136/ bmjopen-2020-037129

- Prepublication history for this paper is available online. To view these files, please visit the journal online (http://dx.doi org/10.1136/bmjopen-2020037129).

Received 20 January 2020 Revised 29 April 2020 Accepted 29 May 2020

Check for updates

(C) Author(s) (or their employer(s)) 2020. Re-use permitted under CC BY-NC. No commercial re-use. See rights and permissions. Published by BMJ.

${ }^{1}$ Department of Health, Medicine and Caring Sciences, Linköping University, Linkoping, Sweden ${ }^{2}$ Centre for Clinical Research Sörmland, Uppsala University, Eskilstuna, Sweden

${ }^{3}$ Research and Development Unit, Department of Medical and Health Sciences, Linköping University, Linkoping, Sweden ${ }^{4}$ Department of Public Health and Caring Sciences, Uppsala Universitet, Uppsala, Sweden ${ }^{5}$ Faculty of health and Life Sciences, Linnaeus University, Kalmar, Sweden

${ }^{6}$ Department of Cardiology, Linköping University Hospital, Linkoping, Sweden

Correspondence to Dr Emma Säfström; emma.safstrom@liu.se

\section{ABSTRACT}

Objective Even though continuity is essential after discharge, there is a lack of reliable questionnaires to measure and assess patients' perceptions of continuity of care. The Patient Continuity of Care Questionnaire (PCCQ) addresses the period before and after discharge from hospital. However, previous studies show that the factor structure needs to be confirmed and validated in larger samples, and the aim of this study was to evaluate the psychometric properties of the PCCQ with focus on factor structure, internal consistency and stability.

Design A psychometric evaluation study. The questionnaire was translated into Swedish using a forward-backward technique and culturally adapted through cognitive interviews $(n=12)$ and reviewed by researchers $(n=8)$.

Setting Data were collected in four healthcare settings in two Swedish counties.

Participants A consecutive sampling procedure included 725 patients discharged after hospitalisation due to angina, acute myocardial infarction, heart failure or atrial fibrillation. Measurement To evaluate the factor structure, confirmatory factor analyses based on polychoric correlations were performed $(\mathrm{n}=721)$. Internal consistency was evaluated by ordinal alpha. Test-retest reliability $(n=289)$ was assessed with intraclass correlation coefficient (ICC).

Results The original six-factor structure was overall confirmed, but minor refinements were required to reach satisfactory model fit. The standardised factor loadings ranged between 0.68 and 0.94 , and ordinal alpha ranged between 0.82 and 0.95 . All subscales demonstrated satisfactory test-retest reliability $(\mathrm{ICC}=0.76-0.94)$. Conclusion The revised version of the PCCQ showed sound psychometric properties and is ready to be used to measure perceptions of continuity of care. High ordinal alpha in some subscales indicates that a shorter version of the questionnaire can be developed.

\section{INTRODUCTION}

Continuity of care is considered a key indicator of quality of care $^{1}$ and includes the seamless transition, consistent communication, coordination and coherence between healthcare settings and providers. ${ }^{2-4}$ Continuity of care has been defined as 'the extent to which a series of healthcare services is

\section{Strengths and limitations of this study}

The process of translation and cultural adaption is validated using cognitive interviews with patients

- The 721 patients included in the confirmatory factor analysis is a sufficient sample size for evaluating the 27 items.

- Using polychoric correlations is an appropriate method when data are ordinal.

experienced as connected and coherent and is consistent with a patient's health needs and personal circumstances'. ${ }^{5}$ Three dimensions compose continuity of care: informational continuity, interpersonal continuity and management continuity. Informational continuity is the availability of clinical and psychosocial information across encounters and professionals. Interpersonal continuity is the subjective experience of a caring relationship between patients and their healthcare professional. Management continuity is the effective collaboration of teams across care boundaries to provide seamless care. ${ }^{56}$

Continuity of care is most at risk during the transition of the patients from hospital to home. ${ }^{47}$ For cardiac patients, discharge from hospital to home is a critical time involving both physical and psychological challenges as they often need to perform self-care, including monitoring and managing symptoms, handling complex medical regimen, implementing lifestyle changes and psychosocially adapting to a new diagnosis, complications or deterioration. ${ }^{8}$ Further, the period after hospitalisation due to cardiac conditions often involves follow-up at another caregiver, making coordination and continuity of care essential. ${ }^{910}$ However, patients have described the discharge process as fragmented and expressed that the clinical care pathways are hard to understand. ${ }^{11}{ }^{12}$ Inadequate information transfer from hospital to primary care is described in several studies ${ }^{13-18}$ and 
can jeopardise patient safety. ${ }^{19}{ }^{20}$ A quantifiable measure of patients' perceptions of continuity of care can allow healthcare professionals or researchers to detect insufficiencies, examine continuity of care over time and evaluate the impact of interventions. Self-report questionnaires are the most common way to systematically collect information about patient experiences, ${ }^{21}$ and in efforts to improve the quality of care, such evaluations are essential. ${ }^{22}$ The most frequently used questionnaires that quantify continuity of care are the Usual Provider of Care,$^{23}$ the Continuity of Care Index ${ }^{24}$ and the Sequential Continuity. ${ }^{25}$ None of these are conceptually sound since they do not include all dimensions of continuity of care as previously stated, but they focus on the number of physicians that provide patient service; further, they address outpatient settings exclusively. ${ }^{6}$ There are questionnaires that encompass the multidimensionality of continuity of care, that is, the Nijmegen Continuity Questionnaire ${ }^{26}$ and the Chao Perception of Continuity. ${ }^{27} 28$ However, neither of them explicitly addresses the period related to hospital discharge. ${ }^{26} 27$

The Patient Continuity of Care Questionnaire (PCCQ) is a generic questionnaire developed to cover all three dimensions of continuity of care described by Haggerty et $\mathrm{al}^{56}$, and it addresses both the period before and after hospital discharge. The original English version of PCCQ was developed and psychometrically evaluated in Canada. An exploratory factor analysis of 27 items suggested a six-factor solution; however, two items did not load on any factor but were placed in one factor each. ${ }^{29}$ Even though the original PCCQ showed acceptable internal consistency with Cronbach alpha of the factors ranging from 0.68 to 0.88 , there were some limitations regarding the validation of the questionnaire. First, the sample size was smaller than recommended. ${ }^{30}$ Second, the previous validation did not take the ordinal nature of data into account. Treating ordinal data as continuous can result in that the association between an item and a factor seems weaker than it really is, which can lead to that pseudo factors reflecting item difficulty rather than the underlying concept are identified. ${ }^{31}$ Third, according to the explorative factor analysis, two items did not load on any factor. ${ }^{29}$ Exploratory factor analysis is generally a descriptive procedure, and the result needs to be confirmed in new samples. Despite those limitations mentioned previously, PCCQ has the potential to become a clinically useful self-report questionnaire to measure patients' perceptions of continuity of care after hospitalisation.

A validated, clinically feasible questionnaire can be used to evaluate continuity of care and highlight areas where improvement is needed in order to facilitate continuity of care, and it is valuable to continue the validation of PCCQ, by confirming the factor structure in a sufficiently large sample using methods taking the ordinal nature of the questionnaire into account. Therefore, the aim was to evaluate psychometric properties of the PCCQ with focus on factor structure, internal consistency and stability.
METHODS

\section{Design and setting}

A psychometric evaluation study using consecutive inclusion of patients discharged from one university hospital, two county hospitals, and one district hospital in central Sweden was conducted. Data were collected 2017-2019.

\section{Study participants}

Patients were eligible for inclusion if they had been hospitalised due to angina (International Classification of Diseases(ICD): I20.0, I20.1, I20.8 and I20.9), acute myocardial infarction (ICD: I21.0, I21.1, I21.2, I21.3, I21.4 and I21.9), atrial fibrillation (ICD: I48.0, I48.1, I 48.2 and I48.9) or heart failure (ICD: I50.0, I50.1, I50.9 and I42.0). The inclusion criteria were (1) 18 years or older and (2) hospitalised for more than 24 hours. The exclusion criteria were (1) dementia with severe cognitive decline, (2) not able to read or understand Swedish, (3) expected survival of $<3$ months, (4) discharged to a nursing home or (4) resident in another county.

\section{Data collection}

Eligible patients were contacted by mail 4-6 weeks after discharge. In addition to the PCCQ the patients received study information, a written informed consent form, questions on patient demographics and a postage prepaid envelope. One reminder was sent after 4-5 weeks. The final response rate was $52 \%(\mathrm{n}=725)$. Patients responding to the questionnaire tended to be younger and were more often men compared with the non-responders. The most common diagnosis in the non-responders was heart failure. For test-retest analysis, the first 500 patients were consecutively invited to complete the PCCQ once again within 2 weeks, and $58 \%(n=289)$ of the patients responded. Medical charts of included patients were reviewed for length of hospital stay, comorbidities and healthcare utilization 30 days prior to and 30 days after the index hospitalisation.

\section{Questionnaire}

The original version of PCCQ was psychometrically evaluated in 204 orthopaedic and family medicine patients; the mean age was 64.9 years (SD 17.4); and $59.8 \%$ were female. The most primary diagnosis in family medicine patients was pulmonary or respiratory, and in the orthopaedic patients, the most common reason for hospitalisation was fracture. ${ }^{29}$

The 27 items of the PCCQ are scored on a 5-point Likert-type scale with the following response options: 1 (strongly disagree), 2 (somewhat disagree), 3 (hard to decide), 4 (somewhat agree) and 5 (strongly agree). In addition, there is an option to respond, "not applicable' (N/A) to each item. The first section of the PCCQ includes items that address the period prior to hospital discharge, and the second section addresses the postdischarge period. The questionnaire has six suggested subscales: 'information transfer to patients', with six items; 'relationships with providers in hospital', with seven 
items; 'relationships with providers in community', with four items; 'management of written forms', with three items; 'management of follow-up', with three items; and 'management of communication among providers', with four items. Subscale scores are created by calculating the average scale scores; that is, all subscales have a possible score range between 1 and 5 . Higher scores indicate that the patient perceived high continuity of care. ${ }^{29}$

\section{Translation and cultural adaption}

The PCCQ was not available in Swedish, and to ensure that the translated version of the PCCQ measures the same concept as the original version, the process of translation and cultural adaption was guided by the method described by Wild et al, which includes forward-backward translation, harmonisation and cognitive interviews. The backward translation and the harmonisation are essential to ensure that the translated version has the same content and conceptual basis as the source questionnaire, and make it possible to compare the results between different countries or cultures. ${ }^{32}$ In the first step in the translation process, the constructor was contacted and approved the translation of the questionnaire. In the next step, a forward translation was made by a native Swedish-speaking translator fluent in English. The backward translation was done by a native English-speaking translator fluent in Swedish who was blinded to the original version of the questionnaire. The forward and backward translated versions of the questionnaire were compared, and discrepancies were resolved among the two translators and the researchers. This resulted in a prefinal version of the questionnaire that was pilot tested through cognitive interviews using a thinkaloud method ${ }^{33} 34$ with 12 patients who had been hospitalised due to heart failure. The cognitive interviews were conducted by the first and second authors. The patients found the content of the items to be relevant but found the phrasing of some items to be unclear. To increase the readability and culturally adapt the questionnaire to a Swedish setting, the phrasing of a few items was modified by the researchers in consultation with the constructor. Six of the patients who participated in the cognitive interview reviewed this version which led to additional changes of the wording in some of the items. The questionnaire was then reviewed for content validity and wording of items and instructions by an expert panel of eight researchers and nurses. Based on the experts' advice, some changes in the wording of the instruction, response options and items were made. The middle response option was reworded into 'neither agree nor disagree'.

\section{Patient and public involvement}

There was no patient or public involvement in the study design.

\section{Data analysis}

Descriptive statistics were used to present sociodemographic and clinical characteristics of the sample. Mean and SD were used for continuous data, while median and quartiles were used for ordinal data. The item responses were treated as ordered categorical data.

Item statistics were evaluated in terms of score distribution, floor and ceiling effects, and missing data. Floor and ceiling effects were evident if $>15 \%$ of the item responses were distributed to the extremes. ${ }^{356}$ A ceiling effect occurs when patients' scores cluster toward the high end of the measure and refers to the inability of the questionnaire to record if the patient's perception of the measurement is higher than the questionnaire's highest response option. ${ }^{37}$ The distribution of scale scores was evaluated with skewness and kurtosis statistics. The normal distribution has kurtosis and skewness values close to 0 , respectively. If skewness was $<-1$ or $>1$, the distribution of scale scores was considered highly skewed and was analysed using non-parametric statistics. $^{38}$

The factor structure of the PCCQ was evaluated with confirmatory factor analysis (CFA). ${ }^{39}$ Since the response categories in PCCQ are of Likert-type, they were considered to be ordinal; the robust estimator weighted least squares with means and variances (WLSMV) were used. ${ }^{31}$ The WLSMV estimator is based on a polychoric correlations matrix, taking the ordinal nature of data into account. ${ }^{40}$ The response option N/A was coded as missing. Missing data were handled by pairwise deletion, and the CFA was thereby based on 721 observations. The baseline CFA model was the six-factor model with 27 items suggested by Hadjistavropoulos and colleagues. ${ }^{29}$ Based on the findings, compete CFA models were evaluated, including a secondorder model. To evaluate the fit of the models, the following recommended criteria were used: root mean square error of approximation (RMSEA) $\leq 0.06$, Comparative fit index (CFI) of $\geq 0.95$, Tucker-Lewis index (TLI) of $>0.95$ and standardised weighted root mean square residual (SRMR) of $<0.08$. ${ }^{41}$ Factor correlations were evaluated and a correlation of $>0.7$ was considered as strong, $0.3-0.7$ as moderate and $<0.3$ as weak. ${ }^{42}$ Internal consistency was evaluated using an ordinal variant of Cronbach's alpha described by Zumbo and colleagues. ${ }^{43}{ }^{44}$ This reliability coefficient is computed much like the traditional Cronbach alpha but is based on a polychoric correlation matrix rather than a variance-covariance matrix. To be able to compare internal consistency with prior studies on PCCQ the traditional Cronbach alpha is presented as well. Alpha values for scales used in research should not be smaller than $0.7 .{ }^{45}$ In addition, composite reliability, also known as a coefficient omega $(\omega)$, was also calculated. The CR was estimated as

$$
\mathrm{CR}=\frac{\left(\sum \lambda_{\mathrm{j}}\right)^{2}}{\left(\sum \lambda_{\mathrm{j}}\right)^{2}+\sum \epsilon_{\mathrm{j}}}
$$

where $\left(\Sigma \lambda_{\mathrm{i}}\right)^{2}$ is the squared sum of the standardised factor loadings, while the $\Sigma \varepsilon_{\mathrm{j}}$ is the sum of the residual variance. ${ }^{46} 47$

The test-retest reliability of the questionnaire was tested in a subsample of 289 patients, using intraclass correlation coefficients (ICC), two-way mixed-effects model and absolute agreement). ${ }^{48}$ An ICC of $0.70-0.90$ represents good 
reliability and an ICC of $\geq 0.90$ represents excellent reliability. ${ }^{49}$ Test-retest reliability is an important aspect of the questionnaire used to evaluate an intervention or groups of patients over time and indicates that any changes in the scale scores over time are due to changes of the perception of the continuity of care, not due to instable measures. ${ }^{50}$

Statistical analyses were conducted in IBM SPSS V.25 for Windows, Mplus V.7.4 (Muthén \& Muthén, Los Angeles, California, USA) and R V.3.5.1 (the R Foundation for Statistical Computing, Vienna, Austria).

\section{RESULTS}

A total of 725 patients participated in the study. The mean age was 72.4 years $(\mathrm{SD}=10.4)$ and $34 \%(\mathrm{n}=245)$ were women. The main diagnoses at index hospitalisation were acute myocardial infarction 33\% $(n=237)$, atrial fibrillation 27\% ( $\mathrm{n}=194)$, heart failure $20 \%(\mathrm{n}=145)$ and angina $20 \%(\mathrm{n}=141)$. The most common comorbidity was prior myocardial infarction $(44 \%, \mathrm{n}=319)$, followed by heart failure $(31 \%, \mathrm{n}=223)$, stroke $(8 \%, \mathrm{n}=61)$ and chronic obstructive pulmonary disorder $(7 \%, \mathrm{n}=58)$. A total of $13 \%(n=95)$ of the included patients had been readmitted within 30 days after the index hospitalisation. Four of the patients had missing data on all items and were not included in the CFA analyses.

\section{Item statistics}

Ceiling effects (ie, extreme scores $>15 \%$ ) were evident for all items, except for item 22; however, all response options were used. There were missing responses in all items, but only four (items 3, 25, 26 and 27) were left unanswered by more than $5 \%$ of the patients. The N/A option was used most frequently in item 22 ('As far as I am aware, the healthcare staff at the hospital communicated well with people from the municipality (eg, home help service and home healthcare) about my care') and item 26 ('As far as I am aware, the required forms were sent to all the applicable places/care providers'), where a total of $51 \%$ and $18 \%$, respectively, used the N/A option (table 1).

\section{Factor structure}

The baseline model demonstrated unsatisfactorily model fit according to RMSEA $(>0.06)$ and TLI $(<0.95)$, while CFI and SRMR showed an acceptable model fit (table 2). Evaluation of the modification index identified item 15 ('The healthcare staff communicated well with each other while I was in the hospital') as a problematic indicator for 'management of communication' and item 24 ('I have received consistent information about my care from all healthcare staff') as a problematic indicator for information transfer to patients.

As the next step, we scrutinised the factor structure of the baseline model and compared it to the concept and the dimensions of continuity of care. These conceptually based considerations guided the revision of the factor structure that was evaluated in model 2: item 15 is conceptually related to how the patient experienced the relations to the healthcare personal in hospital, and for that reason, it was examined as an indicator for 'relations in hospital'. Item 24 is conceptually related to that care received from different providers is connected in a coherent way, and therefore it was examined as an indicator for management of communication. Of conceptual reasons, we also found item 6 ('I received advice about physical activity and exercise') as a poor indicator for management of communication and conceptually more relevant for information transfer to patients. In the evaluation of model 2, all criteria for a good model fit was met (table 2). The standardised factor loadings ranged from 0.679 to 0.943 (table 3 ). The factor correlations ranged between 0.547 and $0.874(\mathrm{p}<0.001)$ (table 4$)$. The distribution of scale scores was close to normal in all subscales except for information transfer to patients', relations in hospital, 'relations in community' (table 3).

Finally, a second-order factor analysis were conducted to examine if the causal construct, that is, continuity of care is a function of the first-order latent factors from model 2. This second-order model demonstrated reasonable model fit with RMSEA close above 0.06 and satisfactory model fit in all other fit indices (table 2). The factor loadings for the second order model, that is, between the higher order factor and the six factors ranged between 0.750 and 0.964 . Thus, the findings support the that the six factors from model two are all important aspects of continuity of care.

\section{Reliability}

The internal consistency for the final measurement model evaluated by ordinal alpha was excellent for all factors and ranged between 0.82 (management of communication) and 0.95 (relations in hospital and relations in community). The corresponding internal consistency measured with traditional Cronbach alpha ranged between 0.78 and 0.92 (table 3 ).

The composite reliability was satisfactory as well and ranged from 0.81 (management of communication) to 0.96 (relations in community) (table 3 ).

According to the ICC, test-retest reliability for the six factors ranged between good (information transfer to patients, management of forms, management of follow-up and management of communication) and excellent (relations in hospital and relations in community) (table 3).

\section{DISCUSSION}

This study evaluated the psychometric properties of the PCCQ using appropriate statistical analyses for ordinal data and sufficient sample size. After minor revisions, the previous suggested factor structure was overall confirmed. All subscales demonstrated satisfactory internal consistency and test-retest reliability in the present sample.

\section{Translation and cultural adaption}

The process of translation and cultural adaptation brought some challenges, especially due to semantic 
Table 1 Item statistics of the Patient Continuity of Care Questionnaire $(n=725)$

\begin{tabular}{|c|c|c|c|c|c|c|c|c|c|c|c|}
\hline \multirow{2}{*}{$\begin{array}{l}\text { Item } \\
\text { number }\end{array}$} & \multirow[b]{2}{*}{ Items } & \multirow[b]{2}{*}{$\mathbf{n}$} & \multirow[b]{2}{*}{ Median } & \multirow[b]{2}{*}{$q 1-q 3$} & \multicolumn{6}{|c|}{ Item score distribution $\%$} & \multirow{2}{*}{$\begin{array}{l}\text { Missing } \\
\text { data }(\%)\end{array}$} \\
\hline & & & & & 1 & 2 & 3 & 4 & 5 & N/A & \\
\hline 1 & Information about diagnosis & 706 & 5 & $4-5$ & 1.0 & 1.0 & 6.2 & 20.0 & 68.0 & 1.2 & 2.6 \\
\hline 3 & $\begin{array}{l}\text { Information about non-acute } \\
\text { symptoms }\end{array}$ & 685 & 4 & $3-5$ & 7.4 & 6.6 & 22.1 & 26.2 & 24.1 & 8.0 & 5.5 \\
\hline 6 & Advice about physical activity & 701 & 4 & $3-5$ & 14.5 & 3.7 & 17.9 & 21.4 & 30.9 & 9.0 & 2.6 \\
\hline 7 & $\begin{array}{l}\text { Information about follow-up } \\
\text { appointments }\end{array}$ & 708 & 5 & $2-4$ & 4.1 & 3.3 & 9.9 & 21.8 & 55.6 & 2.9 & 2.3 \\
\hline 8 & $\begin{array}{l}\text { Information about treatment after } \\
\text { discharge }\end{array}$ & 700 & 4 & $3-5$ & 13.7 & 5.1 & 16.0 & 19.7 & 26.1 & 16.0 & 3.4 \\
\hline 11 & $\begin{array}{l}\text { Confidence in healthcare staff } \\
\text { before discharge }\end{array}$ & 709 & 5 & $5-5$ & 0.3 & 0.8 & 5.0 & 17.1 & 73.7 & 1.0 & 2.2 \\
\hline 12 & Satisfied with information & 707 & 5 & $4-5$ & 1.5 & 3.3 & 10.1 & 23.4 & 58.3 & 0.8 & 2.5 \\
\hline 13 & Satisfied with emotional support & 708 & 5 & $4-5$ & 1.7 & 2.2 & 11.0 & 22.6 & 56.6 & 3.6 & 2.3 \\
\hline 14 & $\begin{array}{l}\text { Satisfied with opportunities to ask } \\
\text { questions and talk }\end{array}$ & 711 & 5 & $4-5$ & 1.4 & 3.2 & 8.0 & 25.7 & 57.7 & 2.2 & 1.9 \\
\hline 15 & $\begin{array}{l}\text { Healthcare staff communicated well } \\
\text { with each other }\end{array}$ & 709 & 5 & $4-5$ & 1.4 & 2.8 & 13.8 & 24.1 & 53.7 & 2.1 & 2.2 \\
\hline 16 & $\begin{array}{l}\text { Plan for follow-up arranged and } \\
\text { explained }\end{array}$ & 700 & 4 & $3-5$ & 8.4 & 5.7 & 17.2 & 25.5 & 32.6 & 7.2 & 3.4 \\
\hline 20 & $\begin{array}{l}\text { Satisfied with information after } \\
\text { discharge }\end{array}$ & 696 & 5 & $3-5$ & 4.3 & 3.3 & 14.5 & 18.5 & 41.1 & 14.1 & 4.0 \\
\hline 21 & $\begin{array}{l}\text { Satisfied with opportunities to ask } \\
\text { questions after discharge }\end{array}$ & 696 & 4 & $3--5$ & 4.3 & 5.5 & 12.4 & 21.2 & 38.2 & 14.3 & 4.0 \\
\hline 22 & $\begin{array}{l}\text { Hospital communicated well with } \\
\text { municipality }\end{array}$ & 695 & 3 & $1.5-4$ & 11.2 & 2.8 & 15.9 & 6.1 & 9.0 & 51.0 & 4.1 \\
\hline 23 & $\begin{array}{l}\text { Information from hospital to follow- } \\
\text { up doctor }\end{array}$ & 694 & 4 & $3-4$ & 7.3 & 3.6 & 19.7 & 13.7 & 35.7 & 15.7 & 4.3 \\
\hline 24 & $\begin{array}{l}\text { Consistent information from all } \\
\text { healthcare staff }\end{array}$ & 692 & 4 & $3-5$ & 8.4 & 4.0 & 21.1 & 19.6 & 31.9 & 10.5 & 4.6 \\
\hline 25 & Required forms were filled in & 686 & 4 & $3-5$ & 7.0 & 2.3 & 24.4 & 11.3 & 38.3 & 11.2 & 5.4 \\
\hline 26 & Required forms were sent & 686 & 4 & $3-5$ & 9.1 & 2.2 & 26.1 & 10.8 & 28.7 & 17.8 & 5.4 \\
\hline 27 & No forms went missing at discharge & 688 & 4 & $3-5$ & 8.4 & 1.8 & 25.9 & 8.6 & 36.6 & 13.7 & 5.1 \\
\hline
\end{tabular}

N/A, not applicable.

equivalence (eg, do words mean the same thing) and idiomatic equivalence (eg, language used for casual communication), ${ }^{51}$ and some items needed rephrasing. The cognitive interviews were a guide for how to reword phrases for cultural adaptation. For instance, findings from the interviews revealed that the translation of 'provider' was perceived as the hospital or region, and instead the phrase 'healthcare personnel' was suggested. The expert panel advised additional changes in the wording of the instruction, response categories and 
Table 2 Goodness-of-fit indices for the confirmatory factor analyses of the Patient Continuity of Care Questionnaire $(n=721)$

\begin{tabular}{|c|c|c|c|c|c|c|c|c|}
\hline \multirow[b]{2}{*}{ Models } & \multicolumn{3}{|c|}{ Goodness of fit } & \multicolumn{2}{|l|}{ RMSEA } & \multirow[b]{2}{*}{ CFI } & \multirow[b]{2}{*}{ TLI } & \multirow[b]{2}{*}{ SRMR } \\
\hline & $\chi^{2}$ & df & $P$ value & RMSEA & $90 \% \mathrm{Cl}$ & & & \\
\hline Baseline model & 1552.504 & 309 & $<0.001$ & 0.075 & 0.071 to 0.078 & 0.95 & 0.94 & 0.06 \\
\hline Second-order model & 1171.810 & 318 & $<0.001$ & 0.061 & 0.057 to 0.065 & 0.97 & 0.97 & 0.05 \\
\hline
\end{tabular}

Baseline model: model as presented by Hadjistavropoulos et al. ${ }^{29}$ Model 2: item 15 moved to factor relations in hospital, item 6 moved to factor information transfer to patients, and item 24 moved to factor management of communication. Second-order model: factor structure as in model 2, adding a second-order factor. $\mathrm{CFI} \geq 0.95, \mathrm{RMSEA} \leq 0.06$, SRMR $<0.08$, TLI $>0.95$.

CFI, Comparative Fit Index; df, degrees of freedom; RMSEA, root mean square error of approximation; SRMR, standardised weighted root mean square residual; TLI, Tucker Lewis Index.

items which further strengthened the content validity of the translated version of PCCQ.

\section{Item and scale statistics}

All response options were used for all items, which strengthens the validity and reliability in this sample. ${ }^{50} \mathrm{~A}$ ceiling effect was evident in 26 of 27 items. Ceiling effects are common in measures of patient's subjective perception of the care experience, in particular, in questionnaires based on Likert-type response options. ${ }^{37}$ However, the distribution of item responses is highly dependent on the sample and can therefore vary between different settings or groups. It is possible that the ceiling effect is due to the patients participating in this study being satisfied with the continuity of their care. Notable are that since the subscales were skewed and the items were on ordinal level, subscale scores should be analysed using non-parametric analyses.

The PCCQ is currently constructed with a 5-point Likerttype scale, including the N/A option. The advantage of including $\mathrm{N} / \mathrm{A}$ as a response option is that patients can use it when the item is not applicable to their situation instead of being forced to take a stand. This might result in fewer items being omitted. ${ }^{50}$ However, Streiner and colleagues argue against the use of ' $\mathrm{N} / \mathrm{A}$ ' as a response option since $\mathrm{N} / \mathrm{A}$ implies that the patient has not taken a position on the statement, and from a psychometric view, the item still remains unanswered. Rather than using an N/A response option, the rule of thumb should be to use items that are relevant to the sample studied, ${ }^{50}$ which can be obtained by, for instance, the use of item banks. ${ }^{52}$ Even though not including a N/A option might result in patients omitting items that are not relevant to their situation, we recommend exclusion of the N/A option in future validations of the PCCQ.

\section{Factor structure}

The evaluation of the original factor structure demonstrated an acceptable model fit in all indices except RMSEA. Since the RMSEA was $>0.06$, some conceptually based revisions in the factor structure was advocated. ${ }^{4153}$ The changes resulted in improved model fit, which indicates that the new factor structure of the revised PCCQ is a more accurate description of the concept of continuity of care, and the questionnaires' ability to measure information transfer to patients, relations in hospital and management of communication has improved. However, since it is the constructors' advice to calculate the mean score rather than the sum score for the subscales, the changes in the subscales did not affect the scale score significantly.

The evaluation of the second-order factor model strengthens the construct validity and imply that all the six factors are relevant to the construct of continuity of care. This finding is in line with a recent concept analysis, proposing that continuity of care occurs only when all dimensions are aligned and integrated. ${ }^{54}$

\section{Reliability}

The ordinal alpha for the subscales was higher than the recommended $>0.7 .^{50}$ However, Streiner argues that alpha $>0.9$ may be a reflection of that some items are redundant. ${ }^{45}$ The subscales relations in hospital, relations in community and management of forms had an alpha higher than 0.9 , and therefore deletion of items might be considered in any future validation. On the other hand, this problem was not addressed by the patients in the cognitive interviews. One important limitation with the alpha coefficient is the assumption that all factor loadings are the same for all items. It has therefore been criticised as a measure of both reliability and internal consistency. ${ }^{55}$ In contrast, composite reliability take consideration to the variation in factor loadings. ${ }^{46}$ In the present study, both ordinal alpha and composite reliability were similar. However, the traditional Cronbach alpha coefficient was lower than both ordinal alpha and composite reliability. This stresses the importance to use appropriate statistics for ordinal data.

The analysis of test-retest reliability demonstrated satisfactory stability in this sample, indicating that any changes in the scale scores over time are due to changes of the perception of the continuity of care, not due to instable measures.

\section{Methodological aspects}

This study included a sufficiently large group for a CFA. Brown has shown in simulation studies that a sample size of 150-200 can be enough in non-complex models. ${ }^{31}$ 
Table 3 Standardised factor loadings, reliability and scale scores for the final model (model 2 ) of the Patient Continuity of Care Questionnaire $(n=721)$

\begin{tabular}{|c|c|c|c|c|c|c|c|}
\hline & & $\begin{array}{l}\text { Information } \\
\text { transfer to } \\
\text { patients }\end{array}$ & $\begin{array}{l}\text { Relations in } \\
\text { hospital }\end{array}$ & $\begin{array}{l}\text { Relations in } \\
\text { community }\end{array}$ & $\begin{array}{l}\text { Management } \\
\text { of forms }\end{array}$ & $\begin{array}{l}\text { Management } \\
\text { of follow-up }\end{array}$ & $\begin{array}{l}\text { Management of } \\
\text { communication }\end{array}$ \\
\hline 1 & $\begin{array}{l}\text { Information about } \\
\text { diagnosis }\end{array}$ & 0.746 & & & & & \\
\hline 2 & $\begin{array}{l}\text { Information about } \\
\text { prognosis }\end{array}$ & 0.805 & & & & & \\
\hline 4 & $\begin{array}{l}\text { Information about acute } \\
\text { symptoms }\end{array}$ & 0.799 & & & & & \\
\hline 5 & $\begin{array}{l}\text { Information about } \\
\text { medication }\end{array}$ & 0.748 & & & & & \\
\hline 6 & $\begin{array}{l}\text { Advice about physical } \\
\text { activity }\end{array}$ & 0.705 & & & & & \\
\hline 11 & $\begin{array}{l}\text { Confidence in healthcare } \\
\text { staff before discharge }\end{array}$ & & 0.849 & & & & \\
\hline 12 & Satisfied with information & & 0.912 & & & & \\
\hline 13 & $\begin{array}{l}\text { Satisfied with emotional } \\
\text { support }\end{array}$ & & 0.851 & & & & \\
\hline 14 & $\begin{array}{l}\text { Satisfied with } \\
\text { opportunities to ask } \\
\text { questions and talk }\end{array}$ & & 0.886 & & & & \\
\hline 15 & $\begin{array}{l}\text { Healthcare staff } \\
\text { communicated well with } \\
\text { each other }\end{array}$ & & 0.774 & & & & \\
\hline 19 & $\begin{array}{l}\text { Confidence in healthcare } \\
\text { staff after discharge }\end{array}$ & & & 0.938 & & & \\
\hline 20 & $\begin{array}{l}\text { Satisfied with information } \\
\text { after discharge }\end{array}$ & & & 0.924 & & & \\
\hline 21 & $\begin{array}{l}\text { Satisfied with } \\
\text { opportunities to ask } \\
\text { questions after discharge }\end{array}$ & & & 0.904 & & & \\
\hline 25 & $\begin{array}{l}\text { Required forms were } \\
\text { filled in }\end{array}$ & & & & 0.934 & & \\
\hline 26 & $\begin{array}{l}\text { Required forms were } \\
\text { sent }\end{array}$ & & & & 0.943 & & \\
\hline 27 & $\begin{array}{l}\text { No forms went missing } \\
\text { at discharge }\end{array}$ & & & & 0.905 & & \\
\hline 7 & $\begin{array}{l}\text { Information about follow- } \\
\text { up appointments }\end{array}$ & & & & & 0.782 & \\
\hline 8 & $\begin{array}{l}\text { Information about } \\
\text { treatment after discharge }\end{array}$ & & & & & 0.778 & \\
\hline 16 & $\begin{array}{l}\text { Plan for follow-up } \\
\text { arranged and explained }\end{array}$ & & & & & 0.841 & \\
\hline
\end{tabular}


Table 3 Continued

\begin{tabular}{|c|c|c|c|c|c|c|c|}
\hline & & $\begin{array}{l}\text { Information } \\
\text { transfer to } \\
\text { patients }\end{array}$ & $\begin{array}{l}\text { Relations in } \\
\text { hospital }\end{array}$ & $\begin{array}{l}\text { Relations in } \\
\text { community }\end{array}$ & $\begin{array}{l}\text { Management } \\
\text { of forms }\end{array}$ & $\begin{array}{l}\text { Management } \\
\text { of follow-up }\end{array}$ & $\begin{array}{l}\text { Management of } \\
\text { communication }\end{array}$ \\
\hline 22 & $\begin{array}{l}\text { Hospital communicated } \\
\text { well with municipality }\end{array}$ & & & & & & 0.679 \\
\hline 23 & $\begin{array}{l}\text { Information from hospital } \\
\text { to follow-up doctor }\end{array}$ & & & & & & 0.766 \\
\hline \multicolumn{8}{|c|}{ Reliability } \\
\hline \multicolumn{2}{|c|}{ Ordinal alpha } & 0.84 & 0.95 & 0.95 & 0.94 & 0.84 & 0.82 \\
\hline \multicolumn{2}{|c|}{ Cronbach's alpha } & 0.84 & 0.91 & 0.92 & 0.91 & 0.78 & 0.78 \\
\hline \multicolumn{2}{|c|}{ Composite reliability } & 0.89 & 0.95 & 0.96 & 0.95 & 0.84 & 0.81 \\
\hline \multicolumn{2}{|c|}{ Mean } & 3.99 & 4.37 & 4.11 & 3.71 & 3.83 & 3.36 \\
\hline \multicolumn{2}{|c|}{ Skewness } & -1.03 & -1.50 & -1.17 & -0.63 & -0.91 & -0.63 \\
\hline \multicolumn{2}{|c|}{ Kurtosis } & 0.62 & 2.23 & 0.74 & -0.44 & 0.16 & -0.64 \\
\hline
\end{tabular}

ICC, intraclass correlation coefficient.

The study population consisted of cardiac patients from various hospital settings and diagnoses, and the results therefore reflect a wide variety of experiences of continuity of care, which have advantages in terms of generalisability and usability of the questionnaire.

There were multiple sites including study participants. It can be seen as a strength of the study that different types of hospitals were included. On the other side, one can argue that this also might influence the independence of the data. However, the number of sites was too small for multilevel latent variable modelling.

In studies that use mail survey to collect data, it has been found that a possible response bias is that patients who find the research topic important or relevant to their situation are more likely to respond to a questionnaire. ${ }^{56}$
In this sample, response bias might be due to illness when non-responders were older and diagnosed with heart failure. Further, due to expected differences in gender and mean age in different diagnoses, a selection bias cannot be disregarded. Furthermore, the generalisability of this study might have been affected by the response rate since almost half of the patients that filled the inclusion criteria did not respond to the questionnaire. However, the response rate is in line with what can be expected in postal surveys, and the generalisability is strengthened by the fact that the sample is consecutively included and that patients are included from four different hospitals and different diagnoses.

A related problem is the large number of missing data. This can to a large extent be explained by the fact that

Table 4 Factor correlations based on model 2 and the second-order model of the Patient Continuity of Care Questionnaire $(n=721)$

\begin{tabular}{|c|c|c|c|c|c|c|}
\hline & $\begin{array}{l}\text { Information transfer } \\
\text { to patients }\end{array}$ & $\begin{array}{l}\text { Relations in } \\
\text { hospital }\end{array}$ & $\begin{array}{l}\text { Relations in } \\
\text { community }\end{array}$ & $\begin{array}{l}\text { Management } \\
\text { of forms }\end{array}$ & $\begin{array}{l}\text { Management of } \\
\text { follow-up }\end{array}$ & $\begin{array}{l}\text { Management of } \\
\text { communication }\end{array}$ \\
\hline Relations in hospital & 0.790 & & & & & \\
\hline $\begin{array}{l}\text { Management of } \\
\text { forms }\end{array}$ & 0.547 & 0.595 & 0.650 & & & \\
\hline $\begin{array}{l}\text { Management of } \\
\text { communication }\end{array}$ & 0.692 & 0.758 & 0.873 & 0.874 & 0.861 & \\
\hline
\end{tabular}

All factor correlations were statistically significant at a level of $p<0.001$ 
many patients used the N/A response option. To handle this problem in the CFAs, a pairwise deletion was considered more appropriate compared with a listwise deletion to not drop too many observations. Nevertheless, both methods can result in biassed parameter estimates; in particular, if data are missing not at random, that is, that the missing data on a given variable are caused by the subject level of that variable. ${ }^{57}$ In these cases, direct maximum likelihood estimators are commonly recommended. However, the WLSMV estimation is a more appropriate method to handle ordered categorical indicator variables and is often recommended in the literature. ${ }^{31}$ Thus, it cannot be excluded that our procedure to handle missing data has biassed the results.

The internal consistency was evaluated with ordinal alpha since it has been shown to estimate reliability more accurately than Cronbach's alpha when ordinal response scales are used. ${ }^{44}$ Notably, the ordinal alpha values were higher compared with traditional Cronbach's alpha in all factors. It is well known that statistical methods treating ordinal data as continuous can result in attenuated estimates of associations between variables and suggest factors that are artefacts of item difficulty rather than reflections of how the concept is constructed. ${ }^{31} 58$ This stresses the importance to use appropriate statistical methods to evaluate self-rating scales based on ordinal data, such as Likert-type response options.

It is difficult to decide on an optimal time interval for the test-retest and recommendations range from 2 to 14 days. If the interval is too short, there is a risk for recall bias, and if the interval is too long, things might have changed. ${ }^{50}$ Even though we chose an interval of 14 days, and some patients did not answer until another 1-2 weeks, the ICC ranged from good to excellent.

\section{CONCLUSION}

The revised measurement model of PCCQ demonstrated sound psychometric properties regarding factor structure, internal consistency and test-retest reliability in this Swedish sample of cardiac patients. The PCCQ can thereby be used to measure patients' perceptions of factors influencing continuity of care. The high ordinal alpha for some factors indicates that a shorter version of the questionnaire should be considered in future revisions.

Contributors ES, LNa and AS were responsible for the translation of the questionnaire, ES, AS and KÅ were responsible for the analysis and interpretation of data. All the authors, including ML, LNo and TJ, contributed to the critical review of the manuscript for important intellectual content. All authors approved the final version of the manuscript.

Funding This work was supported by Centre for Clinical Research Sörmland/ Uppsala University, Eskilstuna, Sweden FoU-centrum/CKF Sörmland-642411, FoUcentrum/CKF Sörmland-742221, FoU-centrum/CKF Sörmland-859581, Linköping University Sweden and the Medical Research Council of Southeast Sweden FORSS607341, FORSS-749931, FORSS-846301.

Competing interests None declared.

Patient and public involvement Patients and/or the public were not involved in the design, conduct, reporting or dissemination plans of this research.
Patient consent for publication Not required.

Ethics approval Ethical permission to conduct the research was granted by the Regional Ethical Review Board in Linköping (number 2017-226-31, 2017/610-32). All participants gave written informed consent.

Provenance and peer review Not commissioned; externally peer reviewed.

Data availability statement No data are available. The data that have been used are confidential.The Patient Continuity of Care Questionnaire (PCCQ) was translated and used with the kind permission of Heather Hadjistavropoulos. To use the English version of PCCQ, contact Heather.Hadjistavropoulos@uregina.ca. To use the Swedish version of PCCQ, contact Emma.Safstrom@liu.se.

Open access This is an open access article distributed in accordance with the Creative Commons Attribution Non Commercial (CC BY-NC 4.0) license, which permits others to distribute, remix, adapt, build upon this work non-commercially, and license their derivative works on different terms, provided the original work is properly cited, appropriate credit is given, any changes made indicated, and the use is non-commercial. See: http://creativecommons.org/licenses/by-nc/4.0/.

ORCID iD

Emma Säfström http://orcid.org/0000-0001-6548-1042

\section{REFERENCES}

1 Holland DE, Harris MR, Planning D. Discharge planning, transitional care, coordination of care, and continuity of care: Clarifying concepts and terms from the hospital perspective. Home Health Care Serv Q 2007;26:3-19.

2 Gulliford M, Naithani S, Morgan M. What is 'continuity of care'? J Health Serv Res Policy 2006;11:248-50.

3 Dorsky DL, Housley CE. Care continuity between a general Hospital and a community urgent care center. Hosp Top 1981;59:14-17.

4 Spehar AM, Campbell RR, Cherrie C, et al. Advances in Patient Safety - Seamless Care: Safe Patient Transitions from Hospital to Home. In: Battles JB, Marks ES, et al, eds. Advances in patient safety: from research to implementation. volume 1: research findings. Rockville (MD: Agency for Healthcare Research and Quality (US), 2005.

5 Haggerty JL, Reid RJ, Freeman GK, et al. Continuity of care: a multidisciplinary review. BMJ 2003;327:1219-21.

6 Reid R, Haggerty J, McKendry R. Prepared for the Canadian Health Services Research Foundation, the Canadian Institute for health information and the advisory committee on health services of the federal/provincial/territorial Deputy Ministers of Health 2002.. In: Defusing the confusion: concepts and measures of continuity of health care. University of Columbia, 2002.

7 Dharmarajan K, Krumholz HM. Strategies to reduce 30-day readmissions in older patients hospitalized with heart failure and acute myocardial infarction. Curr Geriatr Rep 2014;3:306-15.

8 Dickson VV, Nocella J, Yoon H-W, et al. Cardiovascular disease selfcare interventions. Nurs Res Pract 2013;2013:407608:1-16.

9 Kripalani S, LeFevre F, Phillips CO, et al. Deficits in communication and information transfer between hospital-based and primary care physicians: implications for patient safety and continuity of care. JAMA 2007;297:831-41.

10 Coleman EA, Min S-joon, Chomiak A, et al. Posthospital care transitions: patterns, complications, and risk identification. Health Serv Res 2004;39:1449-66.

11 Valaker I, Norekvål TM, Råholm M-B, et al. Continuity of care after percutaneous coronary intervention: the patient's perspective across secondary and primary care settings. Eur $J$ Cardiovasc Nurs 2017;16:444-52.

12 Lindblom S, Ytterberg C, Elf M, et al. Perceptive Dialogue for Linking Stakeholders and Units During Care Transitions - A Qualitative Study of People with Stroke, Significant Others and Healthcare Professionals in Sweden. Int J Integr Care 2020;20:11.

13 Bolton P, Mira M, Kennedy P, et al. The quality of communication between hospitals and general practitioners: an assessment. J Qual Clin Pract 1998;18:241-7.

14 Gheorghiade M, Vaduganathan M, Fonarow GC, et al. Rehospitalization for heart failure: problems and perspectives. J Am Coll Cardiol 2013;61:391-403.

15 Raval AN, Marchiori GE, Arnold JMO. Improving the continuity of care following discharge of patients hospitalized with heart failure: is the discharge summary adequate? Can J Cardiol 2003;19:365-70.

16 Wilson S, Ruscoe W, Chapman M, et al. General practitioner-hospital communications: a review of discharge summaries. J Qual Clin Pract $2001 ; 21: 104-8$. 
17 Vinker S, Kitai E, Or Y, et al. Primary care follow up of patients discharged from the emergency department: a retrospective study. BMC Fam Pract 2004;5:16.

18 van Walraven C, Seth R, Austin PC, et al. Effect of discharge summary availability during post-discharge visits on hospital readmission. J Gen Intern Med 2002;17:186-92.

19 Dudas V, Bookwalter T, Kerr KM, et al. The impact of followup telephone calls to patients after hospitalization. Am J Med 2001;111:26-30.

20 Moore C, Wisnivesky J, Williams S, et al. Medical errors related to discontinuity of care from an inpatient to an outpatient setting. J Gen Intern Med 2003;18:646-51.

21 De Silva D. Helping measure person-centred care: a review of evidence about commonly used approaches and tools used to help measure person-centred care. London: The Health Foundation, 2014.

22 Rothman ML, Beltran P, Cappelleri JC, et al. Patient-Reported outcomes: conceptual issues. Value Health 2007;10 Suppl 2:S66-75.

23 Breslau N, Reeb KG. Continuity of care in a university-based practice. J Med Educ 1975;50:965-9.

24 Bice TW, Boxerman SB. A quantitative measure of continuity of care. Med Care 1977;15:347-9.

25 Steinwachs DM. Measuring provider continuity in ambulatory care: an assessment of alternative approaches. Med Care 1979;17:551-65.

26 Uijen AA, Schellevis FG, van den Bosch WJHM, et al. Nijmegen continuity questionnaire: development and testing of a questionnaire that measures continuity of care. J Clin Epidemiol 2011;64:1391-9.

27 Hill KM, Twiddy M, Hewison J, et al. Measuring patient-perceived continuity of care for patients with long-term conditions in primary care. BMC Fam Pract 2014;15:191-8.

28 Chao J. Continuity of care: incorporating patient perceptions. Fam Med 1988;20:333-7.

29 Hadjistavropoulos $\mathrm{H}$, Biem H, Sharpe D, et al. Patient perceptions of hospital discharge: reliability and validity of a patient continuity of care questionnaire. Int J Qual Health Care 2008;20:314-23.

30 Norman GR, Streiner DL. Biostatistics: the bare essentials. PMPHUSA, 2008.

31 Brown TA. Confirmatory factor analysis for applied research. Guilford Publications, 2015.

32 Wild D, Grove A, Martin M, et al. Principles of good practice for the translation and cultural adaptation process for patient-reported outcomes (pro) measures: report of the ISPOR Task force for translation and cultural adaptation. Value Health 2005;8:94-104.

33 Mv S, Barnard YF, Sandberg JA. The think aloud method: a practical approach to modelling cognitive processes. Academic Press, 1994.

34 Willis GB. Cognitive interviewing: a tool for improving questionnaire design. Sage Publications, 2004.

35 Hobart J, Riazi A, Lamping D, et al. Improving the evaluation of therapeutic interventions in multiple sclerosis: development of a patient-based measure of outcome. Health Technol Assess 2004;8:1-48.

36 Ware JE, Gandek B, Jr. GB. Methods for testing data quality, scaling assumptions, and reliability: the IQOLA project approach. International quality of life assessment. J Clin Epidemiol 1998;51:945-52.

37 Voutilainen A, Pitkäaho T, Kvist T, et al. How to ask about patient satisfaction? the visual analogue scale is less vulnerable to confounding factors and ceiling effect than a symmetric Likert scale. $J$ Adv Nurs 2016;72:946-57.

38 Bulmer M. Principles of statistics. New York: Dover Publications, 1979.

39 Muthén LK, Muthén BO. Mplus user's guide: statistical analysis with latent variables: User'ss guide. Muthén \& Muthén, 2004.

40 Flora DB, Curran PJ. An empirical evaluation of alternative methods of estimation for confirmatory factor analysis with ordinal data. Psychol Methods 2004;9:466-91.

41 Bentler PM. Cutoff criteria for fit indexes in covariance structure analysis: conventional criteria versus new alternatives. Struct Equ Modeling 1999;6:1-55.

42 McHorney CA, Ware JE, Raczek AE. The mos 36-Item short-form health survey (SF-36): II. psychometric and clinical tests of validity in measuring physical and mental health constructs. Med Care 1993;31:247-63.

43 Zumbo BD, Gadermann AM, Zeisser C. Ordinal versions of coefficients alpha and theta for Likert rating scales. J Mod App Stat Meth 2007;6:21-9.

44 Gadermann AM, Guhn M, Zumbo BD. Estimating ordinal reliability for Likert-type and ordinal item response data: a conceptual, empirical, and practical guide. Pract Assess Res Evaluation 2012;17:1-13.

45 Streiner DL. Starting at the beginning: an introduction to coefficient alpha and internal consistency. J Pers Assess 2003;80:99-103.

46 Raykov T. Estimation of composite reliability for congeneric measures. Appl Psychol Meas 1997;21:173-84.

47 Viladrich C, Angulo-Brunet A, Doval E. A journey around alpha and omega to estimate internal consistency reliability. Annals of Psychology 2017;33:755-82.

48 Koo TK, Li MY. A guideline of selecting and reporting intraclass correlation coefficients for reliability research. J Chiropr Med 2016;15:155-63.

49 Hahn EA, Cella D, Chassany O, et al. Precision of health-related quality-of-life data compared with other clinical measures. Mayo Clin Proc 2007;82:1244-54.

50 Streiner DL, Norman GR, Cairney J. Health measurement scales: a practical guide to their development and use. USA: Oxford University Press, 2015.

51 Beaton DE, Bombardier C, Guillemin F, et al. Guidelines for the process of cross-cultural adaptation of self-report measures. Spine 2000;25:3186-91.

52 Cella D, Gershon R, Lai J-S, et al. The future of outcomes measurement: item banking, tailored short-forms, and computerized adaptive assessment. Qual Life Res 2007;16 Suppl 1:133-41.

53 Xia Y, Yang Y. RMSEA, CFI, and TLI in structural equation modeling with ordered categorical data: the story they tell depends on the estimation methods. Behav Res Methods 2019;51:409-28.

54 Bahr SJ, Weiss ME. Clarifying model for continuity of care: a concept analysis. Int J Nurs Pract 2019;25:e12704.

55 G-JY P. The alpha and the omega of scale reliability and validity. Eur Health Psychol 2014;16:56-69.

56 Fowler Jr FJ. Survey research methods. Sage publications, 2013.

57 Little TD, Jorgensen TD, Lang KM, et al. On the joys of missing data. $J$ Pediatr Psychol 2014;39:151-62.

58 Holgado-Tello FP, Chacón-Moscoso S, Barbero-García I, et al. Polychoric versus Pearson correlations in exploratory and confirmatory factor analysis of ordinal variables. Qual Quant 2010;44:153-66. 